\title{
Zeitreise ins Jahr 2037
}

In einer Mischung aus Bühnenstück und Film hat die IGES-Gruppe auf dem Hauptstadtkongress für Medizin und Gesundheit gezeigt, wie der digitale Patient in 20 Jahren aussehen könnte.

Ein 48-Jähriger hat Schmerzen in der Brust, kurz legt er seinen Handgelenk-Scanner auf die Brust und übermittelt seine Werte an seine digitale, als weibliche Figur im Raum schwebende Allround-Assistentin DINA. Innerhalb von drei Minuten empfängt DINA die Ergebnisse eines Experten: Entwarnung. Als der Patient trotzdem eine ärztliche Telekonsultation verlangt, organisiert DINA einen zehnminütigen Termin innerhalb von zwei Stunden.

Zwischendurch wurde das Theaterstück unterbrochen, um auf Charts die wirtschaftliche und demografische Entwicklung hierzulande in den nächsten 20 Jahren zu zeigen: Bis 2037 fallen demnach fünf Millionen Arbeitskräfte weg, in Deutschland, dem kranken Mann Europas, steigt die Wirtschaftsleistung am langsamsten, die Wettbewerbsfähigkeit wird in den nächsten 20 Jahren stetig sinken, im Gegensatz zu Ländern mit einer höheren Geburtsrate wie etwa Frankreich und Großbritannien.

\section{„Über den Tellerrand hinaussehen"}

In der Diskussion im Anschluss an die Vorführung berichtete Prof. Dr. C. Peter Waegemann, ehemaliger CEO des Medical Records Institute, von einer Bekannten, die nach einer Operation verstarb, weil der Arzt vorhergehende Diagnosen nicht kannte. Er befürworte daher die elektronische Patientenakte und forderte eine Finanzspritze für die Digitalisierung, ähnlich

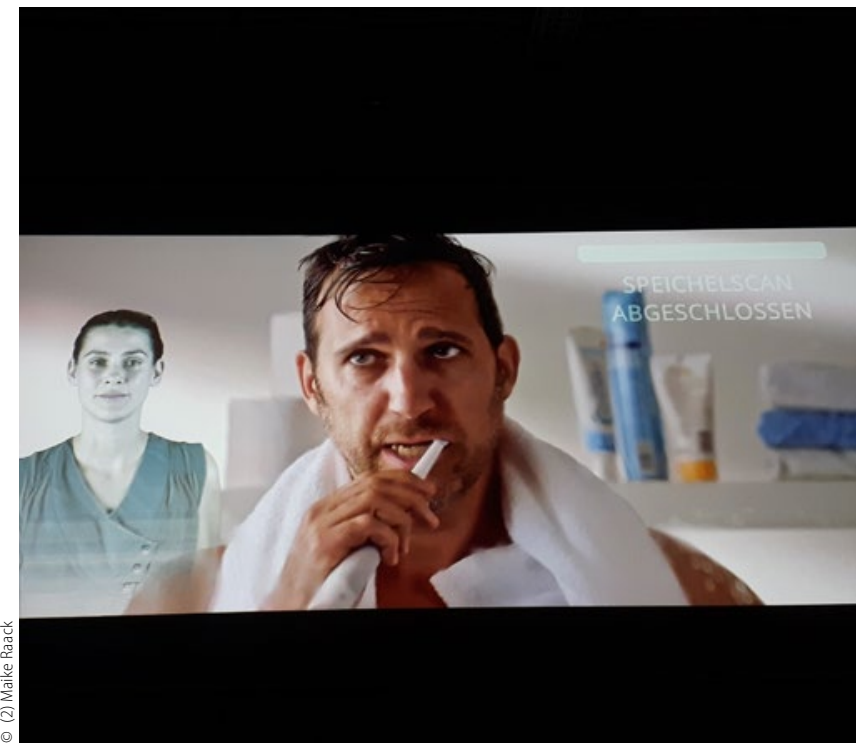

Ein Blick ins Jahr 2037: Der digitale Patient „Tim“ im Gespräch mit seiner digitalen Assistentin DINA wie in den USA und Großbritannien. In allen Ländern der Welt wandle sich der Behandlungsraum in der Praxis oder im Krankenhaus zu einem virtuellen Raum. Darauf müsse man sich hierzulande vorbereiten. „Die Welt bewundert Deutschland für die Leistungen in der Flüchtlingspolitik und der Wiedervereinigung. Wir könnten auch eine ähnliche Rolle in der Digitalisierung einnehmen." Man müsse über den Tellerrand von Normen hinaussehen und die Chance nutzen, besser zu leben und sich besser zu informieren, appellierte er an die Teilnehmer. Deutschland werde sonst den Anschluss verpassen.

Dazu sagte Nils Seebach, Geschäftsführer von Spryker e-Commerce Systems GmbH: „Schon heute erhalten die Patienten mehr Infos von Dr. Google als von einem desinteressierten Arzt, sei es über die Schrittzähler-App oder den StresslevelTest." Die Digitalisierung berge viele Vorteile, werde in Deutschland aber als notwendiges Übel betrachtet. „Die Digitalisierung kommt, es wird aber wohl keine deutschen Player geben“, prophezeite er.

Thomas Ballast, der stellvertretende Vorstandsvorsitzende der Techniker Krankenkasse prophezeite, die ganze Branche werde von außen aufgerollt, wie man sich das heute nicht vorstellen könne. Es sei nicht nur eine Frage neuer technischer Lösungen, sondern vor allem der gesellschaftlichen Akzeptanz.

„Die Ärzte öffnen sich der Digitalisierung“, sagte Franziska Diel, zuständig für Qualität und Entwicklung in Praxen bei der Kassenärztlichen Bundesvereinigung, „man muss aber genau hinsehen, es muss ganz klar einen Mehrwert und Nutzen geben." Die Patienten müssten mit Hilfe der Digitalisierung etwa besser befähigt werden, eigene Kompetenzen zu erhalten.

Maike Raack

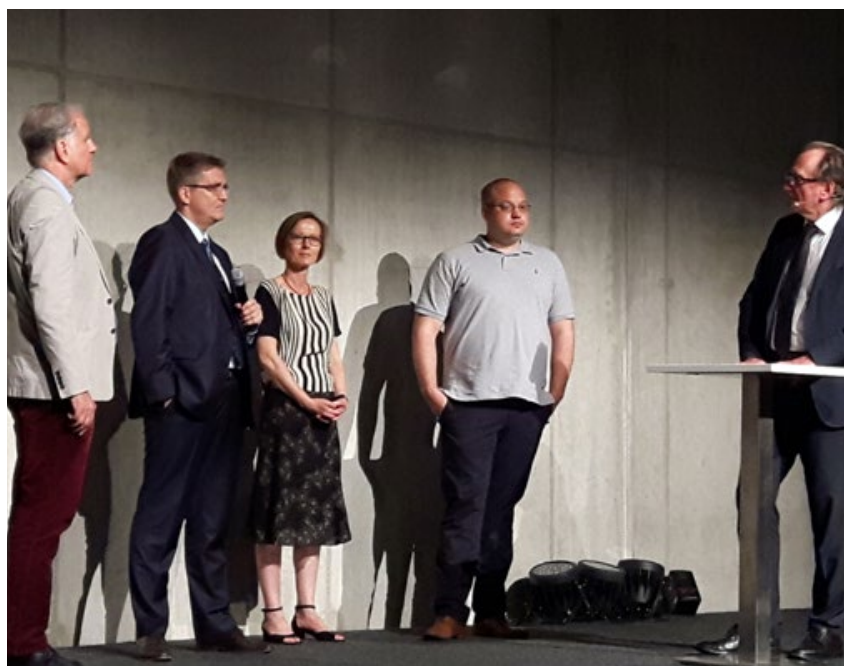

Über die Digitalisierung diskutierten (von links): Prof. Dr. C. Peter Waegemann, ehem. CEO des Medical Records Institute, Thomas Ballast, TKK, Franziska Diel, KBV, Nils Seebach, Spryker e-Commerce Systems GmbH, und Prof. Dr. Bertram Häussler, IGES 